\title{
Immunologic Characterization of Posthepatitis Cirrhosis Caused by HBV and HCV Infection
}

\author{
Wan-Yu Li, Yan-Fang Jiang, Qing-Long Jin, Hong Zhang, Xiang-Wei Feng, and Jun-Qi Niu \\ Department of Hepatology, First Hospital, Jilin University, Changchun 130021, China \\ Correspondence should be addressed to Jun-Qi Niu, junqiniu@yahoo.com.cn
}

Received 9 February 2010; Accepted 14 April 2010

Academic Editor: Young S. Hahn

Copyright () 2010 Wan-Yu Li et al. This is an open access article distributed under the Creative Commons Attribution License, which permits unrestricted use, distribution, and reproduction in any medium, provided the original work is properly cited.

\begin{abstract}
No specific treatment can reverse the liver injury in cirrhosis. This study aims to characterize immune status and correlations between cirrhosis induced by HBV and HCV. Phenotypes of peripheral blood lymphocyte subsets (T, NK, regulatory T cells) and Th cytokine secretion were analyzed using flow cytometry in $42 \mathrm{HBV}$-cirrhotic and $40 \mathrm{HCV}$-cirrhotic patients. Cirrhotic patients had a lower proportion of $\mathrm{CD}^{+} \mathrm{CD}^{+} \mathrm{T}$ cells and NK cells, while the proportion of $\mathrm{CD} 3^{+} \mathrm{CD} 4^{+} \mathrm{T}$ cells and Treg cells were higher than those of healthy controls. The levels of Th2 cytokine (IL-6) in cirrhotic patients were increased, while only the Th1 cytokine $(\mathrm{IFN}-\gamma)$ increased in HBV-cirrhotic patients. These findings show that there is no difference between the cirrhotic groups except in the IFN- $\gamma$ level. In cirrhosis, defects in innate, adaptive immune cells are likely regardless of which virus is involved. A cytokine imbalance may play a role in the development of posthepatitic cirrhosis.
\end{abstract}

\section{Introduction}

Cirrhosis is the twelfth leading cause of death, accounting for 27,000 deaths each year worldwide. It is caused mostly by hepatitis B and C infection, alcoholism, and autoimmune liver diseases. Hepatitis B virus is probably the most common cause of cirrhosis in most of the world, but in the United States and Western countries, chronic alcoholism and hepatitis $\mathrm{C}$ are the most common causes [1]. Ten to thirty percent of patients with chronic hepatitis B develop liver cirrhosis, and up to $20 \%$ with chronic hepatitis C develop cirrhosis [2]. Conventional treatment for cirrhosis can stop or slow progression of the disease and reduce complications, but it cannot reverse liver damage. Consequently, understanding the disease process, making appropriate risk stratification, and implementing treatment require a valid and precise understanding of the immune status.

Although the pathogenesis of viral chronic liver disease is not well understood, there is a consensus that the liver damage is immune-mediated [3]. The importance of innate, adaptive immune responses in combating hepatitis virus infections and progression is poorly characterized. Most of the studies indicate that HBV and HCV usually evade early and late immune responses. HBV, a hepadnavirus, and HCV, a flavivirus, have distinct viral structures, replication mechanisms, pathogenesis, and kinetics. However, they share several aspects of natural history and adaptive immune responses [4]. An infection with HCV or HBV activates the immune system to defend the host with a broad range of innate and adaptive immune responses. Some reports on the immunopathogenesis of chronic HBV and HCV infection have suggested that CD8 T cells, CD4 T cells, Treg cells, and NK cells as well as cytokines participate in the development of liver pathology [5].

Besides quantitative differences, qualitative changes of the immune response may also play a crucial role in determining the resolution or persistence of infection. To our knowledge, little data have been reported concerning the immune status and mechanisms of cirrhosis. Therefore, this study focused on the proportion of peripheral blood lymphocyte subsets and Th cytokine profiles in cirrhotic patients caused by HBV and HCV infection to characterize functional variations of the immune status and determine the correlation between liver cirrhosis of different causes and their immunologic features. 
TABLe 1: Demographic characteristics and clinical features.

\begin{tabular}{|c|c|c|c|c|}
\hline Characteristics & HBV-Cirrhosis $(n=42)$ & HCV-Cirrhosis $(n=40)$ & $\begin{array}{c}\text { Hepatitis B } \\
\text { Non-cirrhotic }(n=26)\end{array}$ & $\begin{array}{l}\text { Healthy Controls } \\
\quad(n=21)\end{array}$ \\
\hline Sex & 22 male $(52 \%) \neq$ & 20 male $(50 \%) \ddagger$ & 14 male $(54 \%) \neq$ & 11 male $(52 \%) \ddagger$ \\
\hline Age (Years) & $50(33-77) \dagger$ & $55(43-73) \dagger$ & $52(26-70) \dagger$ & $59(27-69) \dagger$ \\
\hline ALT (units/L) & $54.0(13.4-526.6) \dagger$ & $54.5(12.9-191) \dagger$ & $72.5(43.2-458) \dagger$ & $<40$ \\
\hline AST (units/L) & $68.0(22.2-458) \dagger$ & $57.8(19.0-245.6) \dagger$ & $80.3(44.9-487) \dagger$ & $<40$ \\
\hline TBIL $(\mu \mathrm{mol} / \mathrm{L})$ & $41.9(9.4-403.4) \dagger$ & $20.5(10.1-245.6) \dagger$ & $44.6(15.8-368) \dagger$ & $<17.1$ \\
\hline Viral loads $\left(\log _{10}\right.$ copies $\left./ \mathrm{ml}\right)$ & $4.5(3.0-7.3) \dagger$ & $3.6(3.0-5.6) \dagger$ & $4.2(3.0-6.9) \dagger$ & NA \\
\hline \multicolumn{5}{|l|}{ Child-Pugh classification } \\
\hline A & $12(29 \%) \ddagger$ & $13(33 \%) \ddagger$ & NA & NA \\
\hline $\mathrm{B}$ & $19(46 \%) \ddagger$ & $16(40 \%) \ddagger$ & NA & NA \\
\hline $\mathrm{C}$ & $11(25 \%) \ddagger$ & $11(27 \%) \ddagger$ & NA & NA \\
\hline
\end{tabular}

Normal values: ALT, $\leq 40 \mathrm{IU} / \mathrm{L} ; \mathrm{AST}, \leq 40 \mathrm{IU} / \mathrm{L}, \mathrm{TBIL} \leq 17.1 \mu \mathrm{mol} / \mathrm{l} ; \mathrm{HBV}$ DNA and HCV RNA $\leq 3 \log _{10}$ copies/ml; † Data are expressed as median (range); ‡ Data are expressed as \%.

\section{Materials and Methods}

2.1. Patients. A total of 82 cirrhotic inpatients who were treated at the Hepatology Unit of the First Hospital of Jilin University from February 2009 to July 2009 were prospectively included in the study, and 21 healthy donors and 26 hepatitis B patients without cirrhosis served as controls. The diagnosis of cirrhosis was made by clinical signs, including evidence of liver decompensation, and confirmed by liver CT, ultrasound examination, serum liver tests (ALT, alanine aminotransferase; AST, aspartate aminotransferase; TBIL, total bilirubin; ALB, albumin; PT, prothrombin time), and blood cell counts. In 4 cases in which the diagnosis was not clear, cirrhosis was also confirmed by liver biopsy. Twenty patients had normal AST and ALT, and 62 had elevated AST and ALT. The majority (75\%) had serum levels of the virus with over $10^{3}$ copies per $\mathrm{mL}$. Twenty-five percent of patients had undetectable viral loads, of which 11 and 14 patients were HBV- and HCV-cirrhotic patients, respectively. Twentyseven patients had ascites, 10 patients had encephalopathy, and 8 patients had esophageal variceal bleeding. Among the $42 \mathrm{HBV}$-cirrhotic patients, 18 were HBeAg-positive and 24 were $\mathrm{HBeAg}$-negative. Twelve of the HBV-cirrhotic patients included in the study were taking nucleoside/nucleotide analog antiviral therapy. Four of them had undetectable HBV DNA. Patients who received interferon treatment during the previous year before sampling were excluded. Patients with human immunodeficiency virus, other types of hepatitis, or carcinoma were also excluded. The study protocol conformed to the ethical guidelines of the 1975 Declaration of Helsinki and was approved by our institutional Review Committee. Written informed consent was obtained from each participant. Demographic characteristics and clinical features of the patients are summarized in Table 1.

2.2. Virological Assessment. HBsAg, anti-HBs, anti-HBc, $\mathrm{HBeAg}$, anti-HBe, and anti-HCV were determined by enzyme immunoassay kits (Abbott Laboratories and InTec PRODUCTS, Inc.). Quantitation of serum HBsAg was performed by comparing the optical densities of different serum sample dilutions with reference curves (Architect quantitative HBsAg, Abbott, IL). HBV DNA and HCV RNA levels were quantified by hybridization assay (Shenzhen PG Biotech Co., Ltd.).

\subsection{Flow Cytometry. All antibodies were from BD Bio- sciences.}

Tregs were estimated based on the previously published method of Liu et al. [6]. Each sample of isolated lymphocytes was washed and resuspended in a staining buffer containing PBS and $0.1 \%$ BSA. Two $\mu \mathrm{l}$ of fluorescein-conjugated specific antibodies was added to the lymphocytes, vortexed and incubated on ice for 20 minutes. To the cells, $500 \mu \mathrm{l}$ of staining buffer was added and cells pelleted.

Numbers of $\mathrm{T}$ and NK lymphocytes were determined in anticoagulated peripheral blood according to the manufacturer's instructions with the following modifications. To each tube containing $50 \mu \mathrm{l}$ of whole blood, TriTEST CD4 FITC/CD8 PE/CD3 PerCP and TriTEST CD3 FITC/CD16+CD56 PE/CD45 PerCP were added. The samples were incubated at room temperature for 1 hour. Following incubation, erythrocytes were lysed using $1 \mathrm{ml}$ FACS lysing solution (eBioscience Inc., USA). The cells were washed twice with $2 \mathrm{ml}$ PBS buffer [7].

Isotype-matched antibodies were used as controls for all the samples. All the samples were analyzed using a FACSCalibur instrument (BD Biosciences) and Flowjo software. At least 20,000 events per run were acquired.

2.4. Cytokine Production. Levels of Th cytokines (IFN- $\gamma$, TNF- $\alpha$, IL-10, IL-6, IL-4, IL-2) were determined by CBA (BD Pharmingen, USA) based on the previously published method of Ahmed et al. [8]. The concentrations of all six cytokines in each well were calculated using BD CBA Software.

2.5. Statistical Analysis. All clinical and flow cytometry data were compared using the Wilcoxon rank sum test and Chisquare test. SAS version 9.0 software was used. Correlations 
were determined using Spearman's correlation test. Results are given in median (range), unless specified otherwise.

\section{Results}

3.1. Peripheral Blood Lymphocyte Subpopulations. Alterations in the peripheral lymphocyte subsets are shown in Figures 1 and 2. There were no significant differences in lymphocyte subsets between the two cirrhotic groups. However, the proportions of lymphocyte subsets were significantly different between the cirrhotic groups and healthy controls. The $\mathrm{CD} 4 / \mathrm{CD} 8$ ratio and $\mathrm{CD}^{+} \mathrm{CD}^{+}$cells were higher, while the $\mathrm{CD}^{+} \mathrm{CD}^{+}{ }^{+} \mathrm{Foxp}^{+}$cells and NK cells were lower in the cirrhosis groups than in the healthy control group. The increase in the CD4/CD8 ratio was a combined result of a relative increase in $\mathrm{CD}^{+}{ }^{+} \mathrm{CD} 4^{+}$cells and decrease in $\mathrm{CD}^{+}{ }^{+} \mathrm{CD} 8^{+}$cells. The proportion of $\mathrm{CD} 4^{+} \mathrm{CD} 25^{+}$Treg cells in patients was dramatically higher than those in healthy controls. Analysis of lymphocyte subsets showed no difference between the HBV-cirrhotic patients and hepatitis $B$ patients without cirrhosis.

3.2. Relationship of Peripheral Lymphocyte Subsets to Clinical Parameters. Considering the different clinical phenotypes, cirrhotic patients were divided into groups: $\mathrm{HBeAg}$ positive or negative, high or low viral load ( $>5 \log _{10}$ copies $/ \mathrm{ml}$ or $<5$ $\log _{10}$ copies/ml) high or low aminotransferases ( $>80$ units/L or $<80$ units/L), and Child-Pugh A, B, C. No correlation was observed between the viral load, Child-Pugh score, hepatic inflammation or HBeAg status, and the percentage of peripheral lymphocyte subsets. There was no relation between the lymphocytes and nucleoside/nucleotide analog antiviral treatment in HBV-cirrhotic patients. A significant correlation was obtained between HBsAg titers and HBV DNA levels $(\mathrm{R}=.461, P=.015)$.

3.3. Cytokine Production. Changes in levels of Th cytokines are summarized in Table 2. No differences in Th1 or Th2 cytokine patterns were observed between cirrhotic groups, except for IFN $-\gamma$, which was dramatically higher in HBVcirrhotic patients than that in HCV-cirrhotic patients $(P=$ .037). IL-6 concentrations were higher in cirrhotic patients than those in controls. The IFN- $\gamma / \mathrm{IL}-6$ ratio in cirrhotic groups was dramatically lower than that in controls $(P=$ .035). However, serum TNF- $\alpha$, IL-2, IL-4, and IL-10 concentrations did not differ among these three groups.

3.4. Relationship of Cytokine Levels to Clinical Parameters and Peripheral Lymphocyte Subsets. IL-6 levels were significantly different among Child-Pugh A $(n=36), \mathrm{B}(n=50)$, and $C(n=30)$ groups $(P=.002)$. They were highest in the $\mathrm{C}$ group and lowest in the A group $(P=.0013)$. The association between levels of IL- 6 stratified by TBIL less than twice and greater than 5-times the upper limit of normal (34.2 and 88.5 U/L, resp.) and $\mathrm{HBsAg}$ titer twice the upper limit of detection $(500 \mathrm{IU} / \mathrm{ml})$ among cirrhotic patients was further analyzed. IL-6 levels in the cirrhotic groups were significantly lower in individuals with $<34.2 \mathrm{U} / \mathrm{L}$ TBIL $(n=39)$ compared to those with $>88.5 \mathrm{U} / \mathrm{L}(n=38)$ $(P=.012)$. IL-6 levels in the HBV-cirrhotic group were significantly higher in patients with $<500 \mathrm{IU} / \mathrm{ml} \mathrm{HBsAg}$ titer $(n=29)$ compared to those with $>500 \mathrm{IU} / \mathrm{ml}(n=32)$ $(P=.031)$.

\section{Discussion}

Innate host responses during the early phases of viral infections are characterized by the activation of NK cells [2]. The current study found a reduced frequency of NK cells in post-hepatitis cirrhosis which is in agreement with previous research indicating an inadequacy of innate host response and inefficient initiation of adaptive immune response [9, 10]. We also showed that no difference was found between the nonviremic and viremic groups, which is inconsistent with the results of Zarife et al. [7]. Different methodologies, including the CD45 labeling, smaller sample sizes, and differences in severity of disease, might explain why some of the findings in these studies differed from ours. The decrease of NK cells could be a hallmark of innate immunity in cirrhotic individuals. As discussed previously, low levels of these cells in cirrhotic patients may be due to intrahepatic compartmentalization or induction of apoptosis of virusspecific immune cells in the development of optimal immune responses [11]. However, published data do not support this possibility.

The cellular immune response has been shown to be a major contributor to HBV and HCV clearance [12]. We detected a shift in the $\mathrm{CD} 4 / \mathrm{CD} 8$ ratio, due to a relative increase in the number of $\mathrm{CD} 4^{+} \mathrm{T}$ cells and decrease in the number of $\mathrm{CD} 8^{+} \mathrm{T}$ cells [13]. The observed defect in CD8 cells is consistent with previous reports. The precise mechanism responsible for this impaired T-cell response is not known. One interpretation is that activation-induced cell death results in a vast amount of T-cell deletions as demonstrated in chronic HBV infection. Another possible interpretation is that the high frequency of Tregs had an immunosuppressive effect on the T-cells. Previous studies have demonstrated that restoration of HBV- and HCVspecific T-cell reactivity was induced by antiviral treatment. Therapeutic strategies aimed at correcting defective T-cell reactivity could represent a complementary approach to the treatment of chronic viral hepatitis [5, 12-15]. Our data may provide theoretical foundations for antiviral treatment in post-hepatitis cirrhosis to some extent. Our study demonstrated that the impaired immunity in cirrhotic patients is accompanied by an augmented Treg cell population which is identical to previous studies [16]. In addition, it has been recently shown that the decline of circulating Tregs coincided with a partial recovery of the immune response during antiviral treatment in chronic hepatitis B. This indicates that the frequency of circulating Tregs is inversely correlated with the strength of the immune response and is associated with viral persistence. Furthermore, in our study, no difference of lymphocyte subsets was observed between the HBV-cirrhotic patients and noncirrhotic hepatitis B 

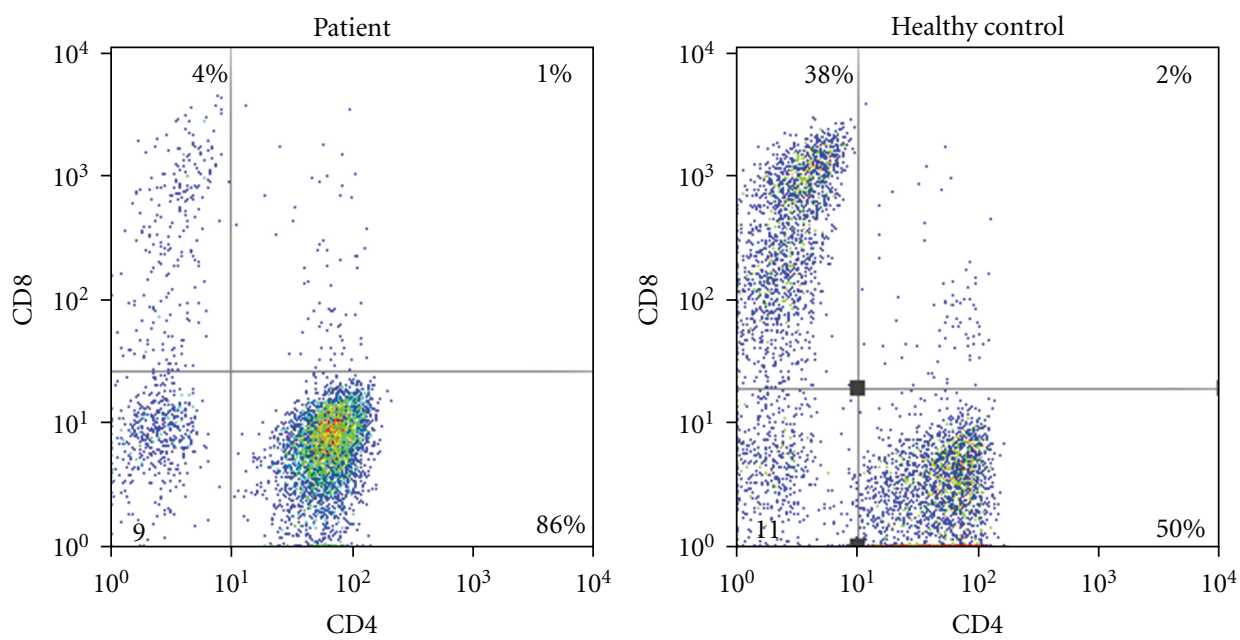

(a)
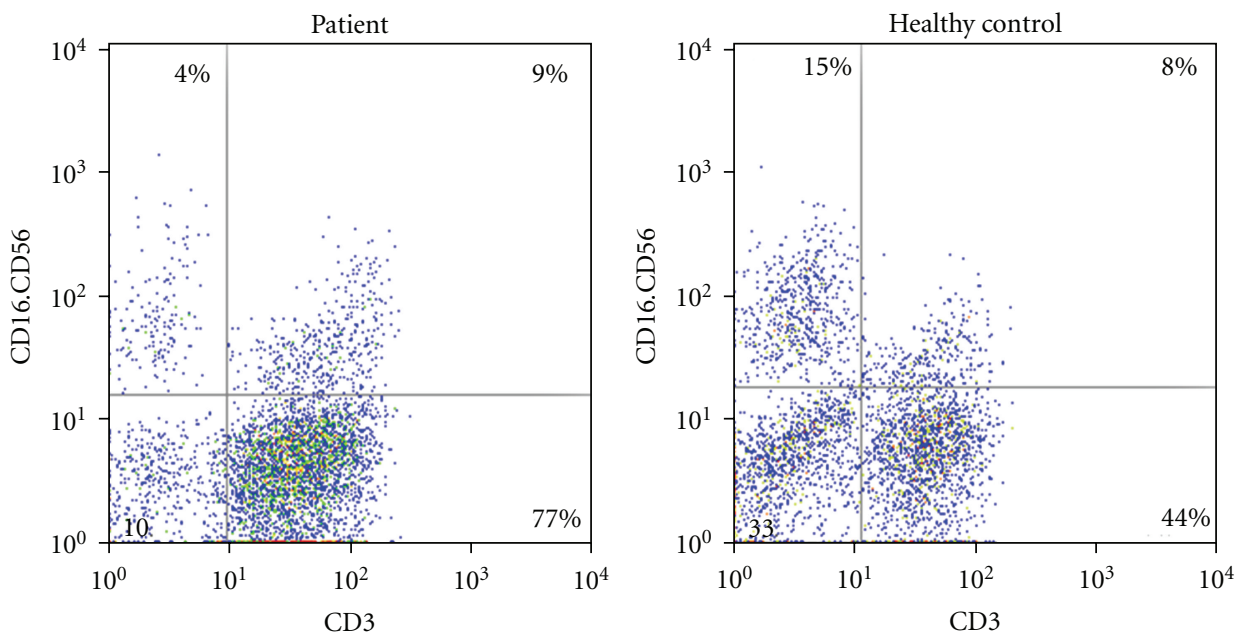

(b)
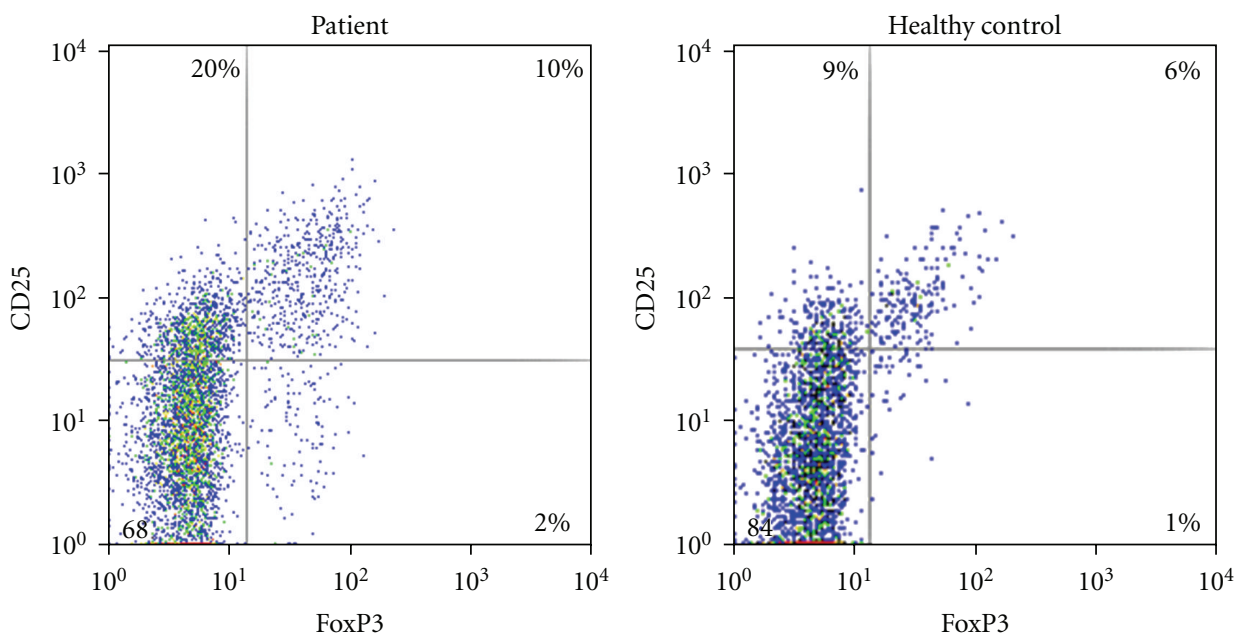

(c)

FIgURE 1: Flow cytometry results from a series of representative patients and healthy controls. (a) The cells in the upper left quadrant and the lower right of the dot plot are $\mathrm{CD}^{+} \mathrm{CD}^{+} \mathrm{T}$ and $\mathrm{CD}^{+} \mathrm{CD}^{+} \mathrm{T}$ cells, respectively. (b) The cells in the upper left quadrant are $\mathrm{NK}$ cells. (c) The cells in the upper right quadrant of the dot plot are CD $4^{+} \mathrm{CD} 25^{+}$Foxp $3^{+}$Treg. 


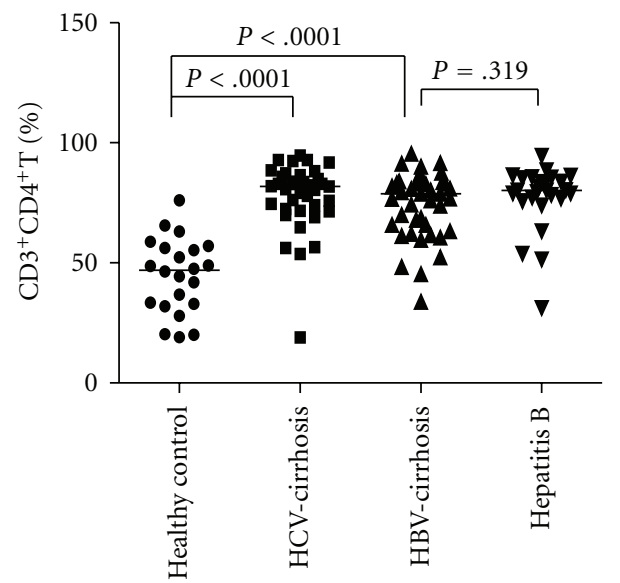

(a)

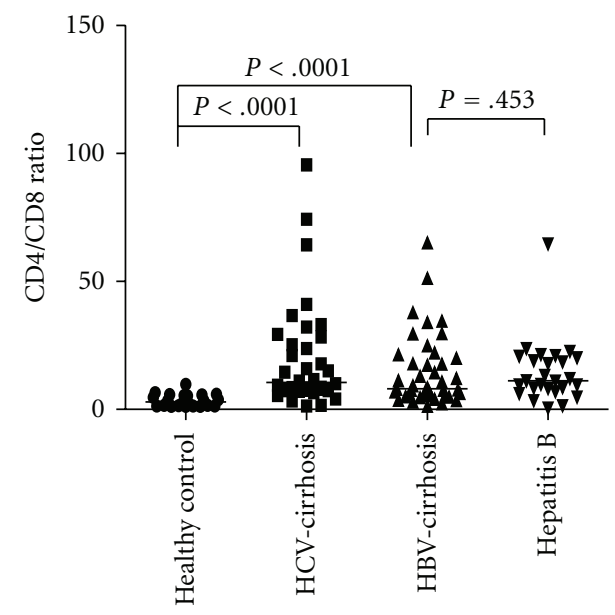

(c)

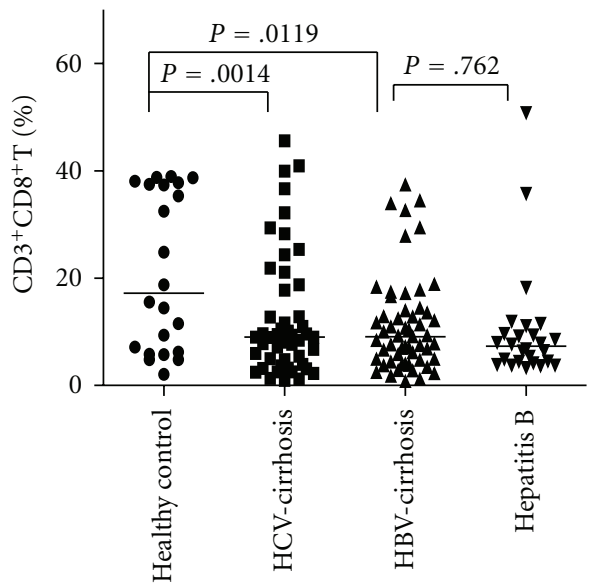

(b)

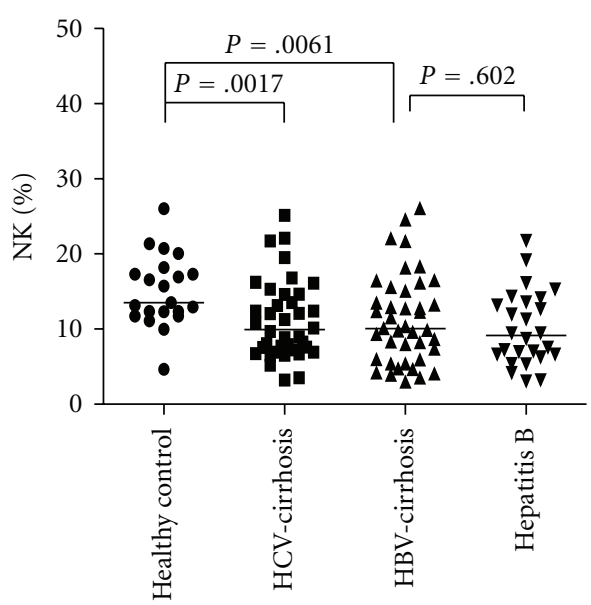

(d)

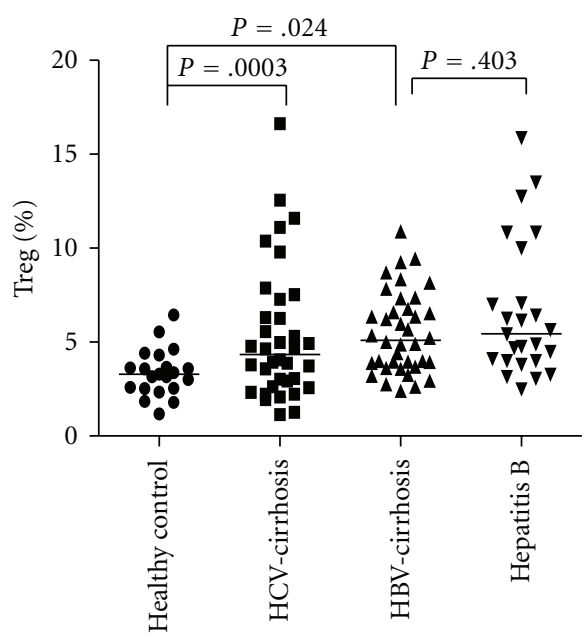

(e)

Figure 2: Illustration of lymphocyte subsets in cirrhotic patients and healthy controls. Each symbol represents an individual, and the medians are shown. (a) $\mathrm{CD}^{+} \mathrm{CD}^{+} \mathrm{T}$, (b) $\mathrm{CD}^{+} \mathrm{CD}^{+} \mathrm{T}$, (c) CD4/CD8 ratio, (d) NK, (e) Treg. 
TABLE 2: T-Lymphocyte cytokine subsets of healthy and cirrhosis patients.

\begin{tabular}{lcccr}
\hline Cytokines $(\mathrm{pg} / \mathrm{ml})$ & HBV-cirrhosis $(n=42)$ & HCV-cirrhosis $(n=40)$ & Healthy controls $(n=20)$ & \multicolumn{1}{c}{$P$ value } \\
\hline IL-2 & $2.3(0.5-41.2)$ & $2.3(0.9-27.3)$ & $2.3(0.6-10.1)$ & $\dagger .4658, \neq .8798$ \\
IL-4 & $2.8(0.6-37.9)$ & $2.7(0.7-45.2)$ & $3.0(1.4-14.9)$ & $\dagger .7125, \neq .860$ \\
IL-6 & $11.7(2.1-100.3)$ & $9.1(2.1-102.2)$ & $2.5(1.8-11.9)$ & $\dagger<.0001, \neq<.0001$ \\
IL-10 & $2.7(1.0-39.4)$ & $2.7(0.5-32.0)$ & $1.6(1.0-28.4)$ & $\dagger .121, \neq .05$ \\
TNF- $\alpha$ & $2.0(0.9-22.9)$ & $1.8(0.8-18.1)$ & $1.6(0.7-21.8)$ & $\dagger .1205, \neq .7624$ \\
IFN- $\gamma$ & $7.9(1.6-84.5)$ & $4.8(1.2-91.6)$ & $4.4(1.8-84.5)$ & $\dagger .0022, \neq .2787$ \\
\hline
\end{tabular}

Data are expressed as median (range); †HBV-cirrhosis versus healthy controls, $\ddagger \mathrm{HCV}$-cirrhosis versus healthy controls.

patients, which indicated that the difference in lymphocyte proportions between cirrhotic patients and healthy controls was not likely to be due to pancytopenia secondary to hypersplenism.

An imbalance of Th1 and Th2 may exert a critical influence on the inflammatory environment and the final outcome of infection $[17,18]$. In our observations, cirrhotic patients showed Th2 profile cytokine secretion dominated by the production of IL-6, which is in agreement with the results of Lee et al. [19]. IL-6 is a bidirectional cytokine with immune-suppressive properties and a hepatoprotective role [20-22]. In our study, serum IL-6 levels correlated positively with Child-Pugh scores and TBIL. This implies that serum IL-6 levels in cirrhosis may reflect the degree of the disease severity and affect the metabolism of bilirubin. Furthermore, serum IL-6 levels had a negative correlation with the HBsAg titer which indicates a potential role of IL6 in inhibiting and eradicating the virus and viral protein. The result confirms the findings of Feldmann et a1. which showed that a decreased clearance of IL- 6 is associated with cirrhosis [23].

Th1 cytokines are involved in cell-mediated immunity and play a crucial role in protection from intracellular pathogens [18]. Previous reports have shown that IFN- $\gamma$ may directly inhibit virus replication and mediate liver injury [24-27]. In our study, serum IFN- $\gamma$ levels were elevated in HBV-cirrhosis, but normal in HCV-cirrhosis. Bertoletti et al. compared liver cytokine profiles of hepatitis $\mathrm{B}$ and $\mathrm{C}$ demonstrating that the livers of hepatitis $\mathrm{B}$ patients had predominantly Th2 cytokines, while hepatitis $\mathrm{C}$ patients had predominantly Th1 cytokines [18]. Although the number of patients in our study was small, the difference in IFN- $\gamma$ levels in HBV- and HCV-cirrhosis was likely related to the type of viral infection rather than to experimental conditions. The data showed that antiviral immune responses are different in $\mathrm{HCV}$ and HBV infections, and these differences may have pathogenetic implications. The following three major interpretations may be drawn. (1) The normal levels of serum IFN- $\gamma$ in HCV infection may be due to the IFN- $\gamma$ migration to the liver, which was demonstrated indirectly by Bertoletti et al. [18]. However, we have no data on intrahepatic cytokines. (2) IFN- $\gamma$ can be regarded as an attempt by the immune system to inhibit viral replication and to eradicate the infection. However, this mechanism would be insufficient to achieve viral clearance in HCV infection. But, it could contribute viral persistence, as generally observed in HCV infection, while the noncytolytic clearance of HBV requires IFN- $\gamma$ and TNF- $\alpha$ [27]. (3) The same observation, however, is also consistent with a threshold phenomenon in which the loss of IFN- $\gamma$ production occurs only at or near the development of HCV-cirrhosis. Our study is consistent with this hypothesis in that IFN- $\gamma$ production in $\mathrm{HCV}$ infected patients with cirrhosis represents a selective defect in the immune repertoire (possibly induced by HCV itself) [28]. Therefore, the development of HCV-cirrhosis would not result primarily from the cytokine, but rather from other mechanisms or combinations with other cytokines $[18,24,25]$. With respect to the balance of Th1 and Th2 cytokines, the ratio of IFN- $\gamma$ to IL- 6 in cirrhotic groups was dramatically lower than that in healthy donors indicating a shift to a Th2 cytokine profile which differs in many respects from the study of chronic hepatitis $\mathrm{C}$ patients [24]. The negative effects of post-hepatitis cirrhosis on the IFN- $\gamma /$ IL-6 axis strongly support a Th2 predominance in the peripheral blood of cirrhotic patients indicating an unfavorable outcome $[25,26]$.

Our data additionally confirmed previous observations that HBsAg titers were positively correlated with HBV DNA. A significant reduction in serum HBsAg titer has been observed with antiviral therapy [29]. Therefore, HBsAg quantitation may be a surrogate marker for response before, during, and after antiviral treatment.

In summary, lymphocyte subsets and cytokine production were found to display different patterns between cirrhotic patients and healthy donors. The hypothesis of inadequate innate and adaptive immunity in the cirrhotic stage can be better tested by performing a longitudinal study including viral carriers, acutely infected, chronic, and resolved patients. The present findings also need to be confirmed by a study of a larger number of samples and further follow-up.

\section{Acknowledgments}

This study was supported by grants from the Eleventh Fiveyear Plan for AIDS and Viral Hepatitis (no. 2008ZX10002004), Ministry of Health (no. 20073531), National Natural Science Foundation of China (no. 30771912), and Jilin Province Science and Technology Agency (no. 200705128). W.-Y. Li and Y.-F. Jiang contributed equally to this work. 


\section{References}

[1] National Digestive Diseases Information Clearing House, "Cirrhosis," January 2008.

[2] A. Bertoletti and A. J. Gehring, "The immune response during hepatitis B virus infection," Journal of General Virology, vol. 87, no. 6, pp. 1439-1449, 2006.

[3] W. N. Chen, H. Feng, J. Zhang, and X. Li, "HBX-Mediated migration of HBV-replicating HepG2 cells: insights on development of hepatocellular carcinoma," Journal of Biomedicine and Biotechnology, vol. 2009, Article ID 930268, 6 pages, 2009.

[4] T. Manigold and V. Racanelli, "T-cell regulation by CD4 regulatory $\mathrm{T}$ cells during hepatitis $\mathrm{B}$ and $\mathrm{C}$ virus infections: facts and controversies," Lancet Infectious Diseases, vol. 7, no. 12, pp. 804-813, 2007.

[5] Y. Kondo, S. Asabe, K. Kobayashi, et al., "Recovery of functional cytotoxic $\mathrm{T}$ lymphocytes during lamivudine therapy by acquiring multi-specificity," Journal of Medical Virology, vol. 74, no. 3, pp. 425-433, 2004.

[6] W. Liu, A. L. Putnam, Z. Xu-Yu, et al., "CD127 expression inversely correlates with FoxP3 and suppressive function of human CD4+ T reg cells," Journal of Experimental Medicine, vol. 203, no. 7, pp. 1701-1711, 2006.

[7] M. A. S. Zarife, E. A. G. Reis, T. M. A. Carmo, et al., "Increased frequency of $\mathrm{CD} 56^{\text {Bright }} \mathrm{NK}$-cells, CD $3{ }^{-} \mathrm{CD} 16^{+} \mathrm{CD}^{-} 6^{-} \mathrm{NK}-$ cells and activated $\mathrm{CD} 4^{+} \mathrm{T}$-cells or B-cells in parallel with $\mathrm{CD} 4^{+} \mathrm{CDC} 25^{\text {High }}$ T-cells control potentially viremia in blood donors with HCV," Journal of Medical Virology, vol. 81, no. 1, pp. 49-59, 2009.

[8] S. F. Ahmad, A. Pandey, K. Kour, and S. Bani, "Downregulation of pro-inflammatory cytokines by lupeol measured using cytometric bead array immunoassay," Phytotherapy Research, vol. 24, no. 1, pp. 9-13, 2010.

[9] C.-T. K. Tseng and G. R. Klimpel, "Binding of the hepatitis C virus envelope protein E2 to CD81 inhibits natural killer cell functions," Journal of Experimental Medicine, vol. 195, no. 1, pp. 43-49, 2002.

[10] Y. Xiao, J. Hendriks, P. Langerak, H. Jacobs, and J. Borst, " $\mathrm{CD} 27$ is acquired by primed B cells at the centroblast stage and promotes germinal center formation," Journal of Immunology, vol. 172, no. 12, pp. 7432-7441, 2004.

[11] Z.-X. Liu, S. Govindadarajan, S. Okamoto, and G. Dennert, "NK cells cause liver injury and facilitate the induction of T cell- mediated immunity to a viral liver infection," Journal of Immunology, vol. 164, no. 12, pp. 6480-6486, 2000.

[12] M. J. Koziel, "Cellular immune responses against hepatitis C virus," Clinical Infectious Diseases, vol. 41, no. 1, pp. S25-S31, 2005.

[13] J. You, H. Sriplung, A. Geater, et al., "Impact of viral replication inhibition by entecavir on peripheral $\mathrm{T}$ lymphocyte subpopulations in chronic hepatitis B patients," BMC Infectious Diseases, vol. 8, article 123, 2008.

[14] T. J. Tang, J. Kwekkeboom, S. Mancham, et al., "Intrahepatic CD8+ T-lymphocyte response is important for therapyinduced viral clearance in chronic hepatitis B infection," Journal of Hepatology, vol. 43, no. 1, pp. 45-52, 2005.

[15] H. Zhang, L.-Y. Wu, S. Zhang, et al., "Anti-hepatitis B virus $\mathrm{X}$ protein in sera is one of the markers of development of liver cirrhosis and liver cancer mediated by HBV," Journal of Biomedicine and Biotechnology, vol. 2009, Article ID 289068, 6 pages, 2009.
[16] J. N. Stoop, R. G. van der Molen, C. C. Baan, et al., "Regulatory $\mathrm{T}$ cells contribute to the impaired immune response in patients with chronic hepatitis B virus infection," Hepatology, vol. 41, no. 4, pp. 771-778, 2005.

[17] S. Sobue, T. Nomura, T. Ishikawa, et al., "Th1/Th2 cytokine profiles and their relationship to clinical features in patients with chronic hepatitis C virus infection," Journal of Gastroenterology, vol. 36, no. 8, pp. 544-551, 2001.

[18] A. Bertoletti, M. M. D’Elios, C. Boni, et al., "Different cytokine profiles of intrahepatic $\mathrm{T}$ cells in chronic hepatitis $\mathrm{B}$ and hepatitis C virus infections," Gastroenterology, vol. 112, no. 1, pp. 193-199, 1997.

[19] Y. Lee, U.-S. Park, I. Choi, S. K. Yoon, Y. M. Park, and Y. I. Lee, "Human interleukin 6 gene is activated by hepatitis B virusX protein in human hepatoma cells," Clinical Cancer Research, vol. 4, no. 7, pp. 1711-1717, 1998.

[20] A. Antonelli, C. Ferri, S. M. Ferrari, et al., "High interleukin6 and tumor necrosis factor-alpha serum levels in hepatitis C infection associated or not with mixed cryoglobulinemia," Clinical Rheumatology, vol. 28, no. 10, pp. 1179-1185, 2009.

[21] C.-H. Hung, C.-M. Lee, C.-H. Chen, et al., "Association of inflammatory and anti-inflammatory cytokines with insulin resistance in chronic hepatitis C," Liver International, vol. 29, no. 7, pp. 1086-1093, 2009.

[22] L. Wan, Y.-J. Kung, Y.-J. Lin, et al., "Th1 and Th2 cytokines are elevated in $\mathrm{HCV}$-infected $\operatorname{SVR}(-)$ patients treated with interferon- $\alpha$," Biochemical and Biophysical Research Communications, vol. 379, no. 4, pp. 855-860, 2009.

[23] G. Feldmann, H. D. Nischalke, J. Nattermann, et al., "Induction of interleukin- 6 by hepatitis $\mathrm{C}$ virus core protein in hepatitis C-associated mixed cryoglobulinemia and B-cell non-Hodgkin's lymphoma," Clinical Cancer Research, vol. 12, no. 15, pp. 4491-4498, 2006.

[24] E.-C. Shin, U. Protzer, A. Untergasser, et al., "Liver-directed gamma interferon gene delivery in chronic hepatitis C," Journal of Virology, vol. 79, no. 21, pp. 13412-13420, 2005.

[25] A. Penna, G. Del Prete, A. Cavalli, et al., "Predominant Thelper 1 cytokine profile of hepatitis B virus nucleocapsidspecific T cells in acute self-limited hepatitis B," Hepatology, vol. 25, no. 4, pp. 1022-1027, 1997.

[26] A. A. Byrnes, D.-Y. Li, K. Park, et al., "Modulation of the IL$12 /$ IFN- $\gamma$ axis by IFN- $\alpha$ therapy for hepatitis C," Journal of Leukocyte Biology, vol. 81, no. 3, pp. 825-834, 2007.

[27] J. Jo and R. Thimme, "Immune responses to hepatitis B and C," Hepatology International, vol. 4, supplement 1, pp. S80S85, 2010.

[28] D. D. Anthony, A. B. Post, H. Valdez, D. L. Peterson, M. Murphy, and P. S. Heeger, "ELISPOT analysis of hepatitis $\mathrm{C}$ virus protein-specific IFN- $\gamma$-producing peripheral blood lymphocytes in infected humans with and without cirrhosis," Clinical Immunology, vol. 99, no. 2, pp. 232-240, 2001.

[29] K. Wursthorn, M. Lutgehetmann, M. Dandri, et al., "Peginterferon alpha-2b plus adefovir induce strong cccDNA decline and HBsAg reduction in patients with chronic hepatitis B," Hepatology, vol. 44, no. 3, pp. 675-684, 2006. 


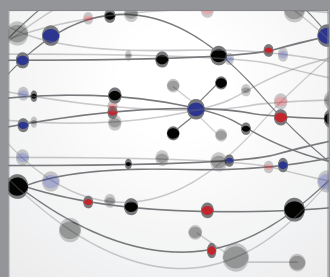

The Scientific World Journal
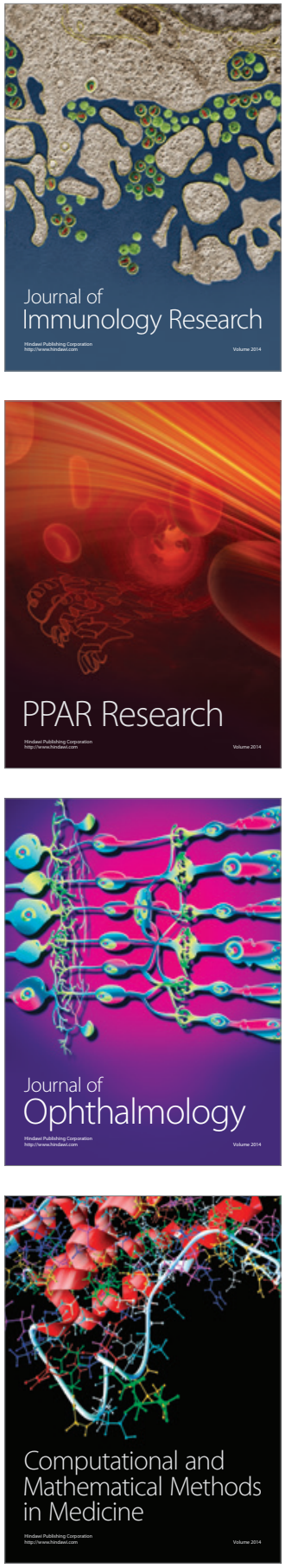

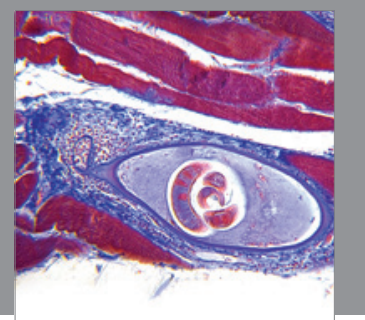

Gastroenterology

Research and Practice
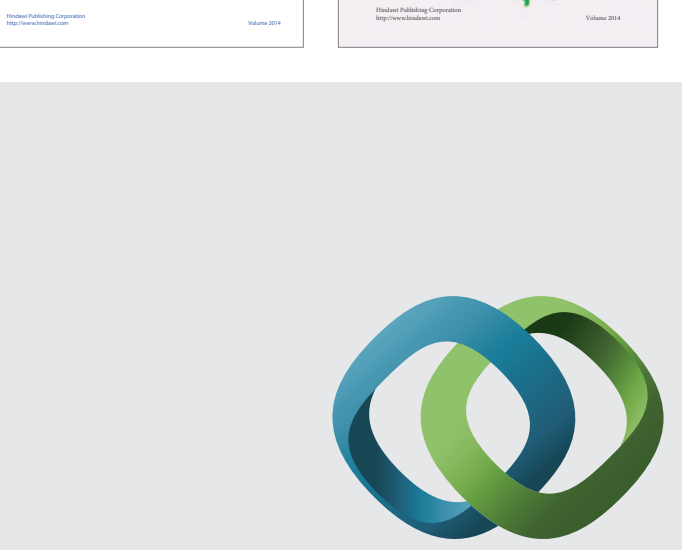

\section{Hindawi}

Submit your manuscripts at

http://www.hindawi.com
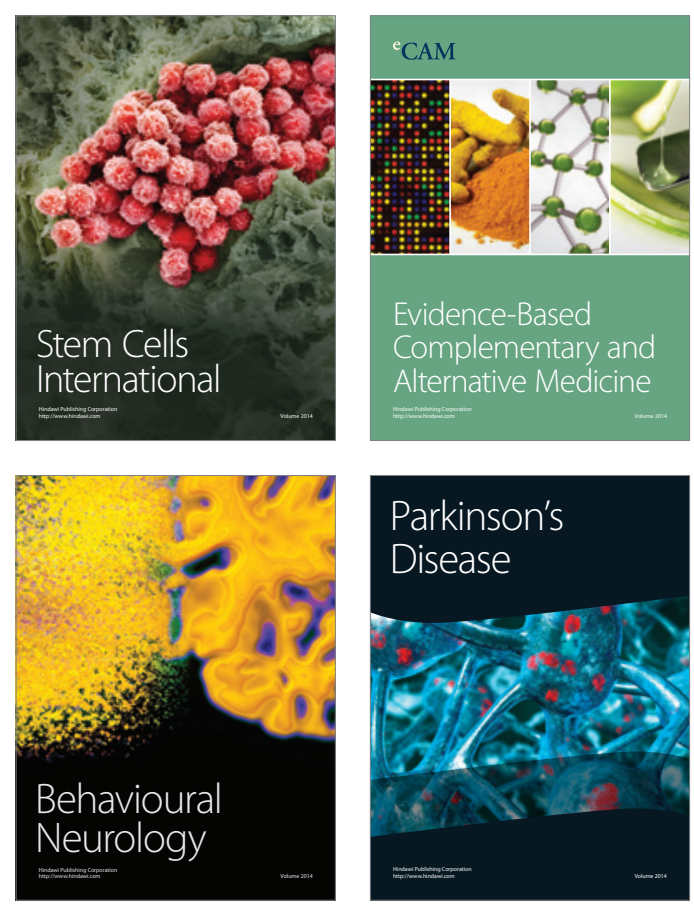

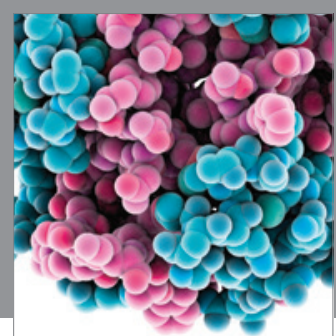

Journal of
Diabetes Research

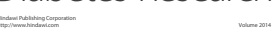

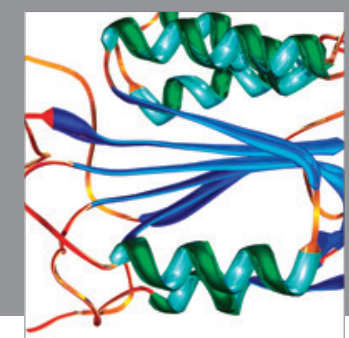

Disease Markers
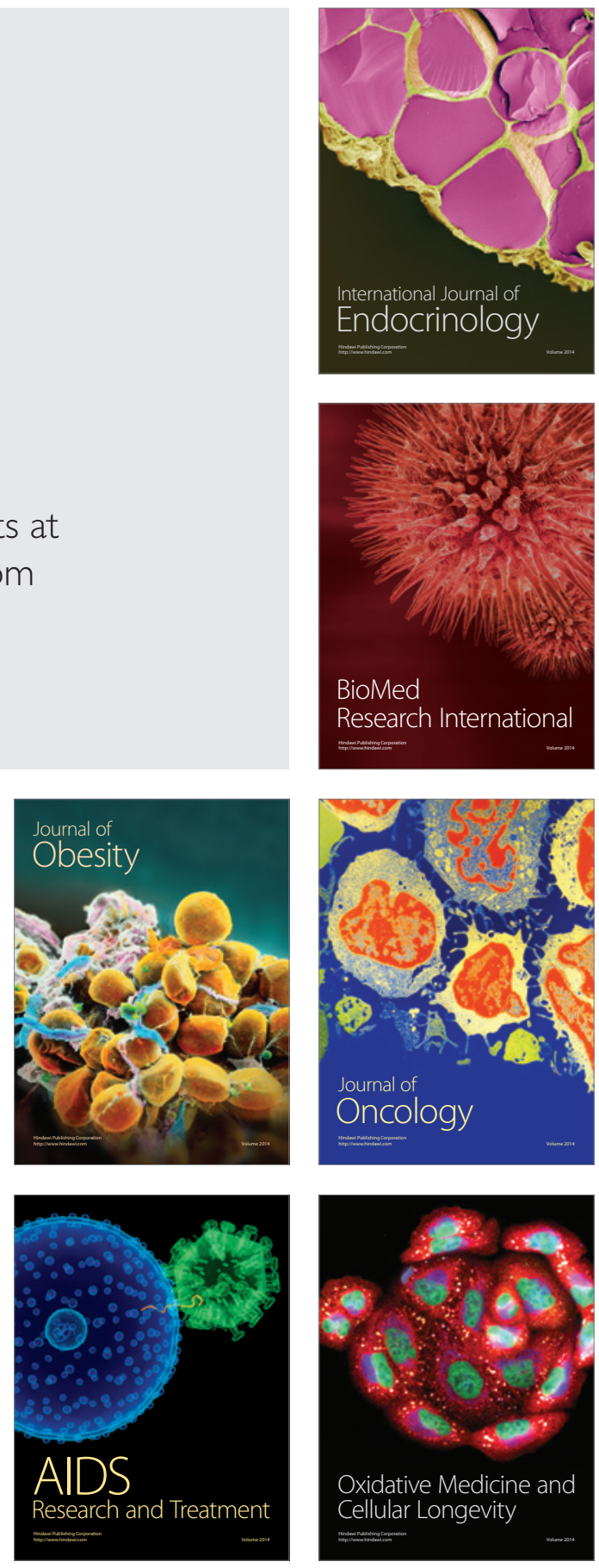